\title{
The global network of tree-ring widths and its applications to paleoclimatology
}

Scott St. George

The width of an annual tree ring is without question a very simple indicator of the character of that year's weather, but collectively, the global network of tree-ring width measurements represents an invaluable resource for high-resolution paleoclimatology.

For over five centuries, it's been known that the annual growth rings of trees in temperate and boreal forests are shaped by variations in weather and climate (Stallings 1937). It was not until the 1960s, however, that research showed how the environmental information recorded in tree-ring widths can be obscured or sharpened by interactions between climate and ecology (Fritts et al. 1965).

Based on these insights, which established the theoretical foundation for the nascent field of dendroclimatology (Fritts 1976; Cook and Kairiukstis 1990), scientists have spent the last five decades developing tree-ring width records at thousands of locations around the world. In part because these data are so widespread and so massively replicated, the combined network of tree-ring widths is now one of the most important sources of proxy climate information on the planet (Solomon et al. 2007; Mann et al. 2008; Villalba et al. 2012; PAGES 2K Consortium, 2013).

The largest archive of tree-ring width data is held within the International Tree-Ring Databank (ITRDB; Grissino-Mayer and Fritts 1997), an open-access database currently maintained by the National Oceanic and Atmospheric Administration (NOAA) in Colorado, USA. Established in 1974 as a permanent repository for digital tree-ring measurements, the ITRDB includes more than 3,200 ring-width records from all continents except Antarctica (Fig. 1). Most records housed by the ITRDB are from North America and Europe, but the archive also includes major regional collections from Siberia (Schweingruber and Briffa 1996), Mongolia (Pederson et al. 2001; Davi et al. 2013), the Tibetan Plateau (Cook et al. 2003; Borgaonkar 2011), the southern Andes (Villalba et al. 2010, 2012), North Africa (Touchan et al. 2011), and New Zealand (Dunwiddie 1979; Ogden and Ahmed 1989). Many more ring-width records are held outside the ITRDB in separate databases operated by research groups and individual scientists.

Recent collection efforts have filled major gaps in the global network in Southeast Asia and India (Cook et al. 2010; Linderholm et al. 2013; Pumijumnong 2013), but despite these successes ring-width records are largely absent from the tropics and much of the Southern
Hemisphere. This is either because the climate of these areas is not seasonal enough to induce dormancy in trees (e.g. in areas such as Amazonia, tropical Africa and Indonesia) or is too arid to support forests (e.g. Saharan Africa, the Middle East and central Australia).

\section{Strengths of network-based analyses}

Because it is made up of thousands of records, which themselves are built from hundreds of thousands of tree-ring series, the data in the global tree-ring width network are replicated to an extent unequalled by any other high-resolution climate proxy.

\section{For each individual record, ring-width} measurements from two to several hundred tree-ring specimens are combined to produce a mean-value function, often called a "chronology". This averaging procedure amplifies the environmental signals shared by most trees and reduces noise related to non-climatic factors such as tree age or ecological disturbance (Cook 1987; Cook and Pederson 2011).

In the same way, but on a grander scale, large networks of tree-ring records allow the

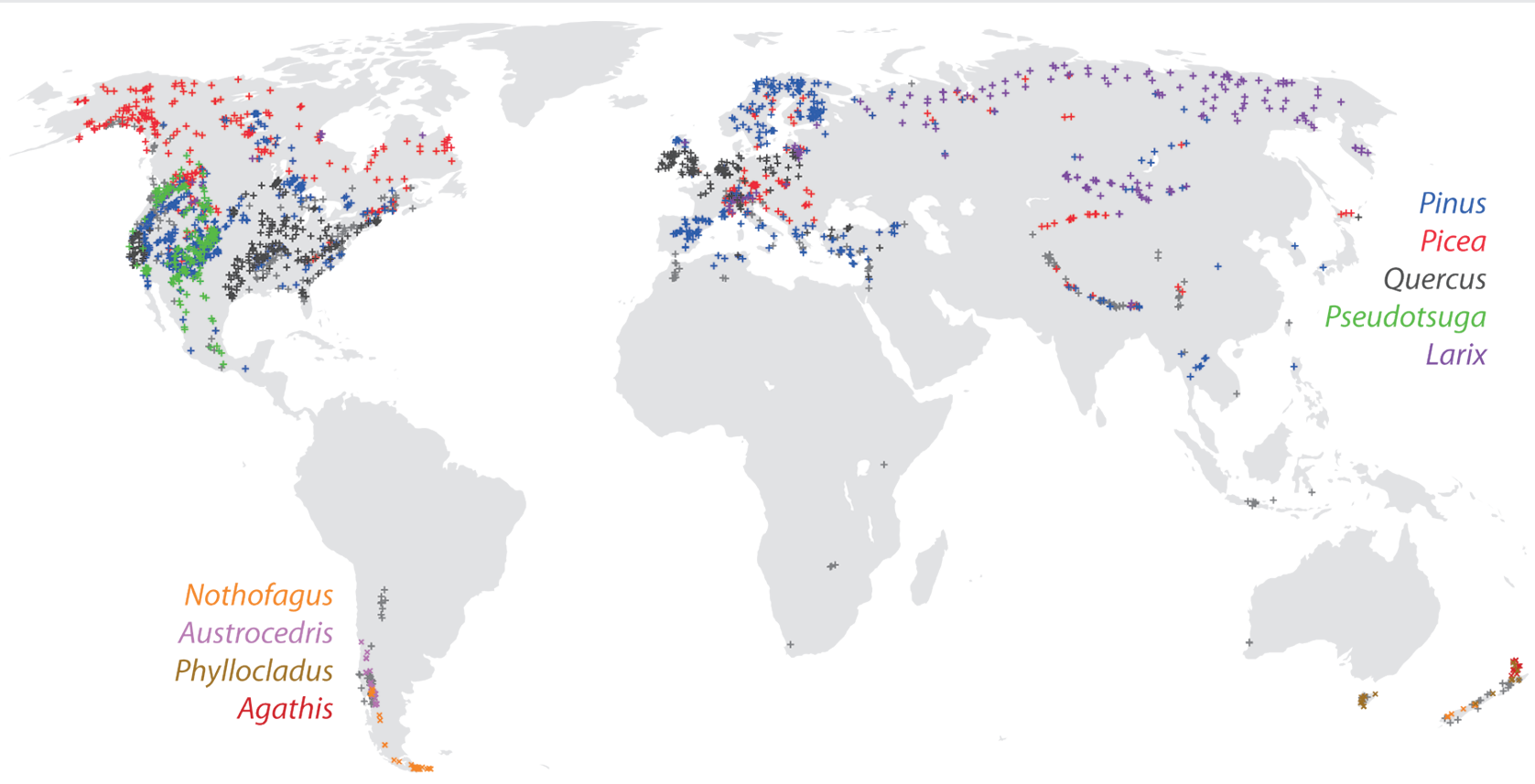

Figure 1: The global network of tree-ring width data held by the World Data Center for Paleoclimatology, NOAA (status 6 July 2012). Colored crosses mark the location of ring-width records from the tree genera most commonly used. Records derived from genera other than those included in the legend are indicated by grey crosses. 


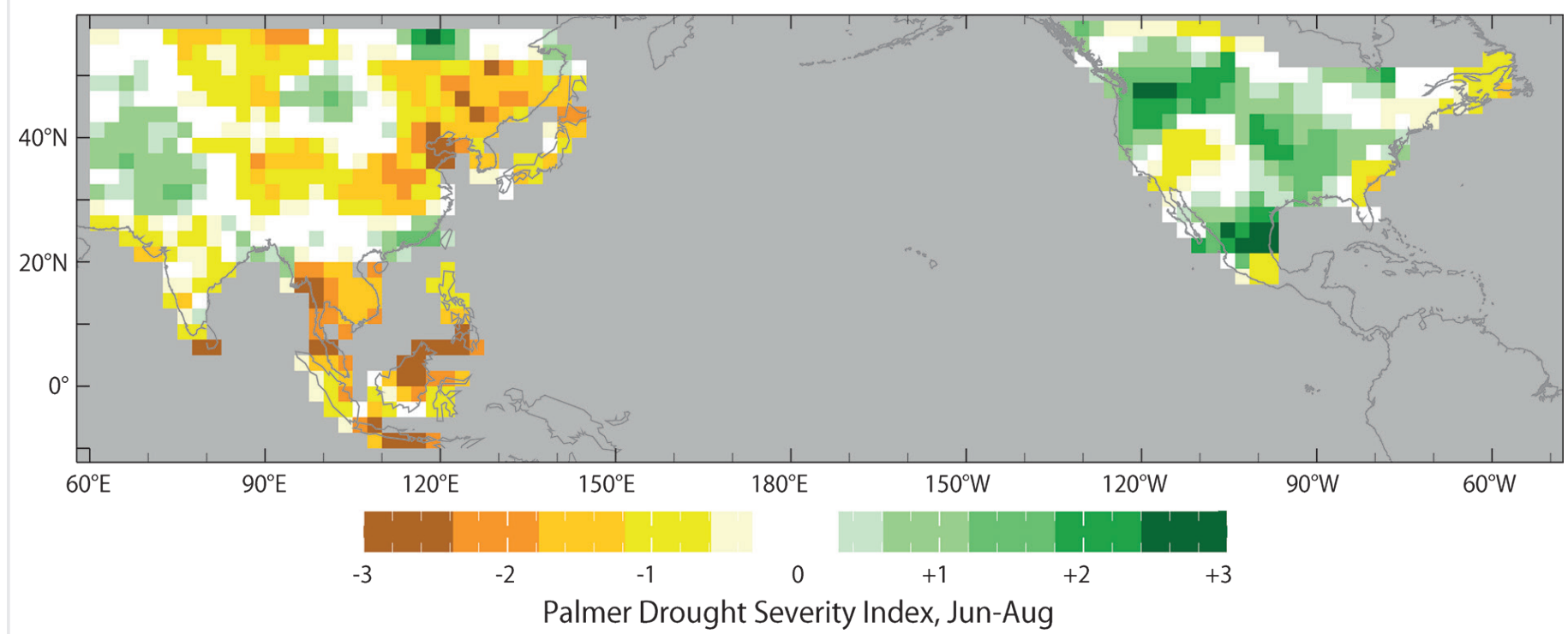

Figure 2: Drought severity in North America (Cook et al. 2004) and monsoon Asia (Cook et al. 2010) during the late Victorian Great Drought of 1876 to 1878 AD. Cook et al. have used ring-widths and other tree-ring parameters to produce year-by-year maps of summer drought severity (as represented by the Palmer Drought Severity Index) extending back to $1 \mathrm{BC}$ in North America and $1300 \mathrm{AD}$ in Asia.

opportunity to assign more weight to behavior shared among many records and tree species, reduce emphasis given to unusual records that may be dominated by non-climatic factors, and (potentially) improve the accuracy of large-scale climate reconstructions (Meko et al. 1993). Networks also allow for the use of reconstruction methods, such as canonical-correlation analysis (Fritts et al. 1971) and principal-component regression (Cook et al. $2004 ; 2010)$, that cannot be applied to small sets of ring-width records.

Large networks can also be used to verify relationships between tree growth and climate that have been identified previously within single records or small collections. Some reconstruction approaches, either explicitly or implicitly, conduct an initial screening to select tree-ring records as potential predictors; however, under some circumstances this process can cause records to be incorrectly identified as sensitive to the target climate parameter (Bürger 2007). Statistical experiments conducted on networks of ring-width records can help distinguish between climate-tree relations that are reliable and those that might be artifacts caused by chance (St. George and Ault 2011).

\section{Paleoclimate products based on \\ tree-ring width networks}

For several decades tree-ring widths have been one of the main proxies used in high-resolution paleoclimatology (Bradley 2011; Hughes 2011) and these data continue to be used regularly as the sole or leading source for paleoclimate reconstructions spanning the late Holocene.

Many products have exploited the extensive replication and broad distribution of tree-ring networks to develop spatially-explicit estimates of past climate at regional, hemispheric or global scales. The leading example of this approach is provided by the North American Drought Atlas (Cook and Krusic 2004; Cook et al. 1999, 2004, 2007), which used a very large set of moisture-sensitive tree-ring width records to generate yearly maps of drought severity across the continent. A parallel product for monsoon Asia was released in 2010 (Cook et al. 2010) and although these reconstructions also incorporated other tree-ring measurements including sub-annual increments and maximum wood density, tree-ring widths were still the main predictors of past drought (Fig. 2).

Large sets of ring-width data have also provided the foundation for proxy estimates of hemispheric and global surface temperatures (Mann et al. 2008), the first near-continental scale reconstructions of precipitation and temperature in the Southern Hemisphere (Neukom et al. 2010, 2011), and most of the regional reconstructions in the recent PAGES $2 k$ synthesis (PAGES 2k Consortium 2013).

Finally, ring-width networks have been used recently to gauge the relative influence of environmental stressors on forest health (Williams et al. 2012), set real-world targets for process models that simulate tree-ring formation

(Tolwinski-Ward et al. 2011; Breitenmoser et al. 2013), and to argue against the hypothesis that major volcanic eruptions caused widespread shutdowns in wood formation in forests across the Northern Hemisphere (St. George et al. 2013; D'Arrigo et al. 2013).

\section{Conclusions}

The width of an annual growth ring is without question a very simple indication of a tree's biological activity and the character of that year's weather. In spite of that simplicity, the millions of observations that make up the global treering network collectively provide us with a powerful and flexible tool to study forest vigor and climate over a broad range of spatial and temporal scales (Cook and Pederson 2011).

As we develop more and more records that describe tree-ring parameters such as maximum latewood density (Briffa et al. 2004), isotopic composition (Csank 2009) or sub-annual increments (Griffin et al. 2011), it should be possible to use analytical methods first applied to tree-ring widths to improve our understanding of tree-climate relations and identify robust climate signals within these other metrics.

Tree rings offer several advantages as a proxy, including their annual or sub-annual resolution and unmatched dating accuracy. However, beyond the archive's own intrinsic qualities, the central role played by ring-width records in modern paleoclimatology is also due to the global network's massive replication and widespread geographic coverage. Those qualities are testament to the dendrochronological community's long-standing commitment to field collection, record development, and data sharing.

\section{ACKNOWLEDGEMENTS}

I am grateful to Bruce Bauer (NOAA), David Meko (University of Arizona), and Toby Ault (Cornell University) for sharing meta-data and code needed to produce the global map of tree-ring widths.

\section{AFFILIATION}

Department of Geography, Environment and Society, University of Minnesota, USA

\section{CONTACT}

Scott St. George: stgeorge@umn.edu

\section{SELECTED REFERENCES}

Full reference list under:

http://www.pages-igbp.org/products/newsletters/ ref2014_1.pdf

Cook ER et al. (2010) Science 328: 486-489

Fritts HC (1976) Tree Rings and Climate, Academic Press, $582 \mathrm{pp}$

Grissino-Mayer HD, Fritts HC (1997) The Holocene 7: 235-228

Neukom R et al. (2010) Geophysical Research Letters 37, doi: 10.1029/2010GL043680

Williams AP et al. (2012) Nature Climate Change 3: 292-297 